\title{
Gender through Their Lenses: A Film of Students' Images
}

\author{
Carol D. Miller \\ University of Wisconsin- \\ La Crosse, La Crosse, \\ Wisconsin, USA
}

cmiller@uwlax.edu

\author{
Mark James Seitz \\ University of Wisconsin-Stout, \\ Menomonie, \\ Wisconsin, USA
}

seitzm0657@my.uwstout.edu

\begin{abstract}
Students in a Sociology of Gender class were each required to provide five digital photos of something they have seen in their worlds that represents beliefs or behaviors related to gender. The photos were organized into themes related to assigned readings on gender and work, family, sexuality, health, education, and more. A short film using their photos was created for them to review and discuss. Once the course-created film was made available for viewing on-line, students were asked a series of questions to assess the effectiveness and reusability of the learning object and the overall assignment. Providing the photographs and viewing a film constructed from them helped students better understand how pervasive gender messages were in their everyday lives.
\end{abstract}

Keywords: Gender, Photographs, Film, Learning Object, Meta-messages

\section{Introduction}

A photo essay was the main project assigned to students in a Sociology of Gender course. The research question answered upon completion of this project was, "Does a film created from students' photographs facilitate understanding of gender messages in their everyday lives?" Students were required to submit a minimum of five photographs of gender in everyday life (Boyle, 1995). First, the students chose specific topics related to the course and then were given four weeks to obtain photographs pertaining to those topics. After they submitted their photos, the images were organized within the different topics and a video was compiled. The effectiveness of this assignment and video were assessed through an on-line survey. The objective of the film compilation of photos was to demonstrate students' abilities to identify relevant and interesting images related to gender in their own lives. While a few obstacles were encountered as the project progressed, and such issues were easily resolved, the film resulting from the assignment demonstrated that

Material published as part of this publication, either on-line or students were able to see gender in their in print, is copyrighted by the Informing Science Institute.

Permission to make digital or paper copy of part or all of these works for personal or classroom use is granted without fee provided that the copies are not made or distributed for profit or commercial advantage AND that copies 1) bear this notice in full and 2) give the full citation on the first page. It is permissible to abstract these works so long as credit is given. To copy in all other cases or to republish or to post on a server or to redistribute to lists requires specific permission and payment of a fee. Contact Publisher@InformingScience.org to request redistribution permission. 


\section{Background: Visualizing Gender in Everyday Life}

According to Bem (1993), cultural beliefs about gender are reinforced in society through our institutions. Meta-messages that women and men are polar opposites - that gender differences are biologically determined and essential and that men are superior or at least the norm to which women are compared and considered inferior - are so pervasive we often do not even realize they are there. She likens the fact that we are immersed and oblivious to gender expectations to the fish that is unaware that it is wet. This assignment was meant to open students' eyes to those meta-messages about gender in their own lives. The assumption was that the students' lived experiences exposed them to visual examples of the sociological concepts discussed in their gender course (Hoop, 2009).

Considering that students' lives have become more visually expressive, through television, film, advertising, YouTube, Facebook, and other social media, the ability to critically analyze visual information has become more important. For example, Howkins (2010) explains that images in print advertising reconstruct values about gender, as well as race, class, religion, and more, in a ritualistic way that portray certain statuses with privilege without the observer realizing it, just by what is centered or placed on the right side of the image or through use of a model's gaze (pp. 5859). She argues that it has become even more critical for students to understand the decisionmaking process of those who produce the images around them, and how those images influence their perspectives on their social world (Howkins, 2010, p. 61). Images from advertising on billboards, in shop windows and on signs around the university campus express values about gender. For the project evaluated in this article, students were required to photograph those images around them and on campus and other examples of how gender was depicted and were asked to analyze what they captured in their snapshots.

Konecki (2009) contends that photographed images can provide an abundant amount of information that can be linked to theoretical categories. From his experience of teaching grounded theory and qualitative methods, he found that photography and visual analyses helped students link their personal experiences with analytical themes (Konecki, 2009, p. 66). However, teaching students how to use visual analysis is challenging, especially in a class of students with diverse experiences using qualitative research methods. As ten Have (2003) explains, very specific instructions need to be provided on how to acquire legal, consensual photographs, and then the analyses have to be broken down into steps in which students are asked specific questions about their photographs that make them apply the theoretical categories. For example, by the end of the semester, a student in ten Have's class wrote a full essay analyzing her photographs of pedestrians and putting them into context with other sociological research on the topics she chose (ten Have, 2003).

Even though specific instructions must be provided to students on how to acquire photographs and analyze them, Tabachnick (2011:129) argues that teachers of such classes must "act more as facilitators rather than experts who impart rules". Students need to have an understanding of what is expected of them and the theories they are to explore, but they also need the freedom to capture the images and discover the stories behind them on their own.

The final stage of the project evaluated in this article involved creating a film compilation of the students' photographs. The film was used as a learning object about gendered messages in everyday life. This accomplished two goals. The main objective was to demonstrate how pervasive gendered messages were in the students' own lives. This demonstration was to stimulate in-class analysis and discussion through technology that this tech-savvy generation prefers (West, Pudsey, $\&$ Dunk-West, 2010, p. 199). Since the video was designed from photographs the students provided from their own lives, they could see themselves as creators of the knowledge presented. The general objective of creating and presenting the film from their photographs was to increase students' understanding of how gender messages exist in their daily lives in ways that create be- 
liefs about gender polarization, biological essentialism and andro-centrism, which are the themes from Bem's Enculturated Lens Theory of gender (Bem, 1993).

\section{Methods}

\section{Population}

Participants were adult university students, 8 males and 21 females, enrolled in an upper division Sociology of Gender course at a Midwestern (U.S.A.) comprehensive state university. Sixteen of the students were seniors, completing their final year of college. Twelve were sociology majors, and eleven majored in psychology. Others were identified as majors in political science, communication studies, biology, exercise and sport science, or the general field of social studies.

\section{Description of the Assignment}

In order to promote understanding of how everyday messages about gender promote specific beliefs about women and men, a photo essay was assigned and film was created from the collection of photos students obtained. On the first day of the spring semester, students received instructions on how to complete a gender photo essay. The first step required them to provide five photographs of examples of gender messages they see in their everyday life. The project was an expansion of a similar assignment by Boyle (1995), in which students were required to investigate gender at the shopping mall. In that example, students were given specific types of stores to visit and were asked to describe items, packaging, and marketing in order to illustrate how toys, videos, greeting cards and more are delineated by gender.

The assignment for this project differed from the "gender at the mall" project in many ways. First, an assumption was made that students were aware of gender messages in their everyday lives and could provide their own examples. Second, they were each allowed to choose two specific topics covered throughout the semester (socialization, sexuality, family and friends, education, paid employment, government and politics, military, health and illness, violence and crime), which provided them more freedom to focus on institutions or social experiences more common to their personal lives. For example, students who were in relationships with someone in the military or who were in the military themselves signed up to investigate gender messages in the military. It was expected that such an assignment would not be an additional burden to them, since they could choose topics and institutions that would be easiest for them to access. Having a choice, although somewhat limited by which slots were left when the sign-up sheet came around, provided some agency to the students to contemplate when and where they could encounter gendered messages.

Finally, instead of written descriptions of the gendered messages they encountered (Boyle, 1995), the students were required to submit digital photographs they took themselves, with captions explaining the photos' relevance to the topics, when and where the photos were taken, and who was in the photo. If they took photographs of people, they needed to acquire signed consent from the subjects or take the photographs in ways that obscured the identities of the individuals. A recent article by Sargent and Corse (2013) described a photo essay assignment with a similar approach and objectives. In their class assignment, Sargent and Corse (2013) required students to create a digital photo essay of gender in everyday life, which included at least 10 annotated photographs. Students in their advanced courses presented their photo essays to the rest of the students in the class, and the instructors facilitated discussions (p. 244). The article describing this assignment was published during the summer following the use of the assignment described and evaluated here, and Sargent and Corse (2013) did not create and evaluate a video learning object that further facilitated student understanding of gender messages in their everyday lives. 
For the assignment described here, the photographs were not due until four weeks after the course began, in order for students to learn about the gender theory they would be applying (Bem, 1993) and to present examples of gender messages around them. In particular, they were exposed to Goffman's analysis of Gender in Advertisements (1979), which is an analysis of how women and men are presented in print advertising in ways that allude to status differences. Students also watched the film Miss-Representation (Siebel Newsome, 2013) in which current examples of how gender is presented or created in the media are examined.

Since this was a visual sociology project (ten Have, 2003), in a second assignment, students were required to analyze the specific ways in which the gendered messages they photographed exemplified gender polarization, biological essentialism, andro-centrism, and/or institutionalized gender. For this, they just needed to write one or two sentences describing how each of their photos fit with the themes of the theory. Finally, they wrote an essay discussing how the gendered messages they photographed related to published sociological research on the topics they chose. This required them to access previous research on their topics (e.g., gender in the military) and either "place" their photo in the context of that research and what they had read and discussed in class, or discuss how their photo did not support what they had learned.

\section{The Learning Object}

Because the objective of the assignment was for students to observe gender messages within the entire collection of images they and their classmates obtained, a video learning object was created from their photo submissions. The second author, who has training in film editing, produced the film. Using digital film-editing software, images were sequenced according to topics related to the sociology of gender course and a soundtrack of music and commentary was added. The process was essentially a larger visual sociology project. Although the photographs were submitted according to topics that the students chose in advance, they were organized within the video according to themes that emerged within those topics. Sometimes a photograph that was submitted for one topic (gender in work and occupations, for example) fit better with a theme found within another topic (like education), so it was moved. The film created from photographs of pink and lavender winter jackets for girls and blue and black jackets for boys and local tavern posters with bikini-clad models announcing Spring Break specials resulted in a ten-minute video learning object. Students were provided a link (http://vimeo.com/62556598) to the learning object and were asked to review it and assess it in terms of its operation and teaching effectiveness.

Once the course-created film (Seitz \& Miller 2013) was made available for viewing on-line, students were asked a series of questions to assess the effectiveness in increasing understanding of gender messages and the reusability of the learning object and the overall assignment. Using questions adapted from a previous assessment of a learning object (Jones \& McNaught, 2005) and other questions assessing what students learned from the video and the project, a survey was created. Institutional Review Board (IRB) approval was acquired for the assessment of the project.

\section{Results}

Students' responses to the assessment questionnaire indicated that the photo-essay assignment and the ten-minute film created from their photographs were effective in helping them understand gender in their society. Three themes emerged as patterns in their answers. The first theme was about how prolific gender messages were in their lives. In response to the question, "In what ways did having to complete this gender photo project facilitate your understanding of gender in everyday life?" one student wrote: 
"Even though I was aware of these differences, until I put myself out there and captured them through my own lens, it didn't sink in quite the same way as reading a book would have done. Now, I'm much more aware of how the gender divisions we live with everyday are a part of nearly all aspects of society, whether they're directly inherent or not."

Another wrote:

"Having to look for these images helped me to recognize the excessive prevalence of these implicit messages of gender polarization, andro-centrism, and biological essentialism. It becomes clear how thoroughly embedded these notions are in our society and how easily it must be to internalize such messages that consistently overwhelm us".

Nine of the students expressed an appreciation for having gender meta-messages drawn to their attention through the photo assignment and in the film.

Through the film compilation of the images the students provided, a second theme about gender polarization was observed. Many of the photos provided demonstrated how children are socialized in different directions through toys and activities and are guided toward separate spheres within social institutions like education and work. Seeing them streamed together in the film facilitated student understanding. The theme of gender polarization was evident in ten of the students' responses to the questionnaire. As one student stated, "It made me aware of how biased our society is and how we try to segregate everything by gender". Another explained:

"It made gender polarization more noticeable. I never really questioned why toys were certain colors or why some toys were only meant for girls. This project has made me more conscious of this".

Another theme that was identified in three students' responses was that they now questioned how natural gender categories were in society. This theme relates to the idea of biological essentialism, that gender differences are the result of biological determinism (Bem 1993). As one student put it, "I learned how blind we are to gender because of how we have been socialized - it seems like a natural thing when really it's very institutional and exists almost everywhere." Only one student expressed a final theme of andro-centrism:

"It reaffirmed my understanding of gender as a master status. We organize almost everything in our society by sex. Although I was previously aware that women have been/are oppressed through this organization, this assignment made me realize just how much they are and that it is accepted as a norm."

Bem (1993) argues that this is a common cultural theme in gender meta-messages. However, since only one student expressed this theme, it cannot be argued that it emerged as a pattern in students' answers.

Through the photo essay project and the film created as a learning object from their photographs, three main themes of Bem's theory (1993) were reinforced: the concepts of gender metamessages, gender polarization, biological essentialism and andro-centrism. One student summarized the effects of the photo essay project and the learning object/film, "It made me realize how much my world is impacted by gender norms. It also gave me a better understanding of what I can do to deter these gender roles and stereotypes as a woman."

\section{Challenges to the Project}

The biggest surprise on this project was the problem getting some students to realize that their world is not on a screen. The assignment was to photograph gender patterns in their lives, but for some students that meant taking screen shots of the websites they frequented or the movies they watched. As it was, more than one student submitted a screen shot of text messages they ex- 
changed, and we included one of those in the video. With a deadline extension and more specific instructions, students submitted better photographs of gender patterns observed in their real worlds. As one student stated, "I think the only challenge, really, was getting myself to open up and think of ideas. Examples of these gender categories are everywhere, and it was easier once I thought about what to do."

This is related to another issue that came up. Students had to be reminded that they could not take photographs of images seen in magazines or books or anywhere else, or by someone else. One student expressed frustration with this, "I found it really hard not using an advertisement for a picture because I find that advertising in today's life shapes how children perceive a lot of what they see." Concerns about copyright violations had to be reinforced.

The weather during the first part of the semester might have contributed to the low number of photographs from "out in their real worlds." As one student wrote, "The weather made it hard to capture outdoor scenes. Maybe have this project later in the semester." Some students submitted photos they had taken previously, so many photos depicted warmer weather and people outdoors with less clothing. However, those students who had to rely on wandering around town looking for photo opportunities had to brave some of the coldest, snowiest weather we have had in a while. Better photographs might have resulted in the early part of fall or later in the spring.

Students' photography skills varied greatly and this posed a challenge as well. Some students were almost too creative and set up shots or staged images that represented the topics they chose. In some cases, the photographs were beautiful, but the meanings were not obvious until the descriptions and analyses were completed. One student photographed three quarters sitting next to four quarters. The meaning of this photo was not apparent until he explained that it represented the "sex gap in pay." Other photographs were quite out of focus or taken from bad angles, so the subjects were difficult to identify. Requesting five photographs from each student ensured that there were plenty of useable shots that could be included in the film.

In order to complete this project by creating a learning object film, someone skilled in film editing needed to be available. Many universities employ videographers and video producers as noninstructional academic staff, as part of a learning technologies department or as members of the public relations or marketing team for the university. Many faculty and students are skilled in video production, as well, so finding someone to assist an instructor should not be too challenging.

\section{Evaluation of the Learning Object}

As indicated in Table 1 the results from the evaluation of the learning object show that the film created from their photographs was well constructed and easy to assess. All of the students who completed this portion of the assessment agreed or strongly agreed that the video operated correctly, was a useful aid to student understanding of concepts, provided opportunities for higher learning and more.

Table 1. Evaluation of Video Learning Object Results

\begin{tabular}{|l|r|}
\hline Evaluation Criteria & $\begin{array}{l}\text { Percent who } \\
\text { Agreed/Strongly Agreed }\end{array}$ \\
\hline The video operated smoothly & $100 \%$ \\
\hline The audio operated smoothly & $100 \%$ \\
\hline The video learning object is free of spelling/grammar errors & $100 \%$ \\
\hline The video learning object is free of informational errors & $100 \%$ \\
\hline
\end{tabular}




\begin{tabular}{|l|r|}
\hline Evaluation Criteria & $\begin{array}{l}\text { Percent who } \\
\text { Agreed/Strongly Agreed }\end{array}$ \\
\hline The content of this video learning object is up-to-date & $100 \%$ \\
\hline The video learning object has made suitable reference to credible references & $95.6 \%$ \\
\hline The content is well organized & $100 \%$ \\
\hline $\begin{array}{l}\text { The video learning object could aid students' understanding of the concept(s) } \\
\text { of topic(s) being presented }\end{array}$ & $100 \%$ \\
\hline $\begin{array}{l}\text { The video learning object provides opportunity for higher-order thinking } \\
\text { The video learning object could be easily incorporated into larger collections } \\
\text { of content }\end{array}$ & $100 \%$ \\
\hline An accurate web address to the video learning objet is given & $95.6 \%$ \\
\hline Overall, I would rate this video learning object highly & $100 \%$ \\
\hline N= & $100 \%$ \\
\hline
\end{tabular}

\section{Conclusions}

It was hypothesized that students in a Sociology of Gender class would gain a better understanding of gender messages in their everyday lives by being required to submit photographs of gender messages around them and through observation of their classmates' photos compiled into a video learning object. Their photographs and responses to the project assessment questionnaire indicated that, if they were not aware of those gender messages in their lives before, they were better able to see them through this assignment. Specifically, students expressed an awareness of how these meta-messages reinforce beliefs, values, and norms about gender polarization, biological essentialism, and andro-centrism. Combining the photo essay project with viewing a film created from all of their photos allowed the students to see how the messages they photographed from their own lives, through their own camera lenses, were part of a larger systemic pattern that was captured through images from all of their classmates.

Based upon the experiences and students' suggestions, future use of this project will require more specific instructions about what is and is not part of their real world. More options for topics might be offered, as well. Additional changes to the ways in which the project was implemented are not really necessary, since the overall results from this first attempt were quite successful and the project will continue to be used in this module.

A photograph assignment and the creation of a film as a learning object could be used to demonstrate other messages besides gender in our society. Students could explore messages about age, race, culture, sexuality, environmental issues, etc. by photographing what exists in their own lives. The important component is requiring students to actively collect and organize the information from the worlds they encounter daily. The simultaneous ownership of the images, while seeing them in the film, set next to images their classmates obtained, had a powerful enlightening effect on understanding social life.

\section{References}

Bem, S. L. (1993). Lenses of gender: Transforming the debate on sexual inequality. New Haven: Yale University Press.

Boyle, C. E. (1995). Seeing gender in everyday life: A field trip to the mall. Teaching Sociology, 23(2), 150-154. 
Goffman, E. (1979). Gender advertisements. New York: Harper \& Row.

Hoop, K. C. (2009). Students' lived experiences as text in teaching the sociological imagination. Teaching Sociology, 37(1), 47-60.

Howkins, M. B. (2010). Visual literacy for the enhancement of inclusive teaching. Human Architecture: Journal of the Sociology Self-Knowledge, 8(1), 57-62.

Jones, J., \& McNaught, C. (2005). Learning object evaluation: Challenges and lessons learned in the Hong Kong Context. In ED-MEDIA 2005. Pp. 3580-3585. G. Richards \& P. Kommers (Eds.). Proceedings of the 17th annual World Conference on Educational Multimedia, Hypermedia \& Telecommunications, Montreal, Canada, 27 June - 2 July. Norfolk VA: Association for the Advancement of Computers in Education.

Konecki, K. (2009). Teaching visual grounded theory. Qualitative Sociology Review, 5(3), 64-92.

Sargent, C., \& Corse, S. M. (2013). Picture my gender(s): Using interactive media to engage students in theories of gender construction. Teaching Sociology, 41, 242-256.

Seitz, M. J., \& Miller, C. D. (2013). Gender through our lenses [Video]. Available from http://vimeo.com/62556598

Siebel Newsom, J. (2012). Mis-representation. Virgil Films and Entertainment.

Tabachnick, D. (2011). Wielding the camera pen: Teaching sociology through filmmaking. Humanity \& Society, 35, 128-148.

ten Have, P. (2003). Teaching students observational methods: Visual studies and visual analysis. Visual Studies, 18(1), 29-35.

West, B., Pudsey, J., \& Dunk-West, P. (2010). Pedagogy beyond the culture wars: De-differentiation and the use of technology and popular culture in undergraduate sociology teaching. Journal of Sociology $47(2), 198-214$.

\section{Biographies}

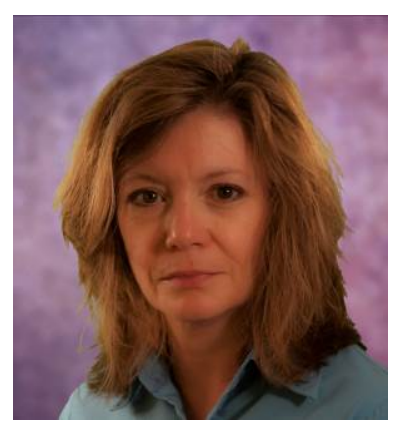

Carol D. Miller earned her Ph.D. from the University of Arizona and is a professor of sociology at the University of Wisconsin-La Crosse. She teaches Sociology of Gender and Global Inequality and conducts research on the effects of globalization and inequality in local communities. She is the author of the book Niagara Falling: Globalization in a Small Town.

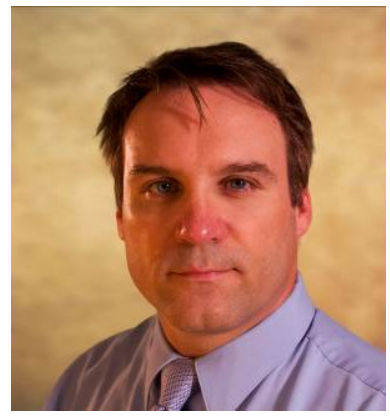

Mark James Seitz is pursuing a Master's degree in Information Communication Technology with an emphasis in Visual Communications at the University of Wisconsin-Stout. 